\title{
Bladder Neck Stenosis
}

National Cancer Institute

\section{Source}

National Cancer Institute. Bladder Neck Stenosis. NCI Thesaurus. Code C78212.

Narrowing or stricture of the bladder neck. 